\title{
EDUCAÇÃO E DIREITO NA SOCIEDADE PORTUGUESA DO SÉCULO XVI
}

\author{
Célio Juvenal Costa \\ Amanda Regina Barbosa Lemes \\ Universidade Estadual de Maringá-UEM
}

\section{RESUMO:}

Propomos, aqui, uma reflexão acerca da relação entre a Educação e o Direito em Portugal, a partir da análise das Ordenações Manuelinas vigentes no século XVI. Num contexto cultural fundamentado na religiosidade cristã, tanto a Educação como o Direito expressavam uma forma de ser lusitana que se manifestava num projeto de sociedade. $\mathrm{O}$ Direito português consubstanciou-se em ordenações reais: as Afonsinas, elaboradas no reinado de D. Afonso V (1438-1481), as Manuelinas, de 1521 e as Filipinas, de 1603. A primeira parte do texto conceitua o Direito e a Educação como construções históricas, culturais e sociais, e estabelece sua mútua relação ao eleger e tutelar os bens sociais mais relevantes. A seguir, mostramos a sociedade portuguesa no século XVI, tendo por base os estudos historiográficos de Antônio Manuel Hespanha, revelando de que forma essa sociedade concebia os seus valores mais fundamentais. E, por fim, procuramos demonstrar, a partir da análise das Ordenações Manuelinas, o direito vigente no período, no qual se encontram os valores emanados da dinâmica histórico-social, valores estes que no contexto histórico apresentam-se como bens sociais, mas ao serem tutelados pelo direito ganham status de bens jurídicos. Para desenvolver a temática proposta, partiu-se do pressuposto de que a Educação pode ser entendida como a formação humana mais geral em uma sociedade, pois toda sociedade acaba por definir qual ser humano é ideal para nela viver e agir e, dessa forma, os comportamentos são definidos socialmente. Outro pressuposto é de que o Direito é fruto de construções sociais, resultado de vários elementos constituídos e exercidos pelos seres humanos em convivência. O que é positivado no Direito, é fruto de valores estabelecidos nas relações sociais, e suas mudanças decorrem de movimentos humanos. Mas, se por um lado a educação é o que forma os indivíduos, propiciando que se internalizem os valores estabelecidos em determinada sociedade desde seus primeiros passos dentro dela, e o direito, por outro lado, vem com intuito de regular as relações estabelecidas por esses indivíduos, também de acordo com os mesmos valores, então podemos dizer que a educação compõe a base do cumprimento legal de uma sociedade. E, ainda, se o direito é constituído de valores a serem cumpridos, e a educação tem o papel de formar os seres humanos dentro desses valores, há uma relação mútua e socialmente fundamental entre o direito e a educação.

Palavras-Chave: Direito; Educação; Ordenações Manuelinas; Portugal; Século XVI

\section{EDUCATION AND RIGTH IN PORTUGAL SOCIETY OF THE XVI CENTURY}

\begin{abstract}
:
The proposal is to reflect upon Education and Right in Portugal having as a starting point the Manuelinas Ordinances as of the XVI century. On a Christian religious fundamented cultural context, both Education and Right expressed a Lusitan way of social organization and planning. The Portuguese Right was raised in Royal basis: Alfonsinas, elaborated on the ruling time of D. Afonso V (1438-1481), the Manuelinas, from 1521, and the Filipinas, from 1603. The 1st part of the essay conceives the Right and Education as historical platform, cultural and social. Establishes a mutual relationship for a social relevant issues.
\end{abstract}


Follows the Portuguese society in century XVI having based on history studies performed by Antônio Manuel Hespanha, where upon the society built its most relevant values. Finally we envisage to demonstrate, from de Ordenações Manuelinas principles, the existing rights and laws during the period which the Right as existing, where values are clearly being raised in its dynamics regarding history and society, these are values that historically grew from a cultural value to law. To develop the issue as proposed we started from the Education as a cornerstone to humanistic formation and development and as an extension to the human society, as all society defines what is human to live and this why behavior is defined $b$ the society. The other starting point is that Right is a collection of social bricks, being built, resulting in several elements and exercised by humans beings by its living together. Rights is conformed by the values determined by the social relations. As education is the basis to raise individuals and building values since the beginning, Right comes as regulatory consequence. Therefore we can state that education as a role in developing people within set values, thus the correlation in between Education and Right. Keywords: Right; Education; Manuelinas Ordinances; Portugal; XVI century

\section{INTRODUÇÃO}

O objetivo, aqui, é mostrar a relação existente entre a Educação e o Direito na sociedade portuguesa do século XVI, mediante a análise do livro V das Ordenações Manuelinas, que era o código de leis vigente em Portugal de 1521 a 1603. Especificamente o último livro das Ordenações, livro V, trata do que hoje se classifica como parte penal, no qual estavam estabelecidos, a rigor, os bens jurídicos que deveriam ser tutelados pelo Estado monárquico lusitano. Antes, porém, estabeleçamos as concepções gerais acerca do Direito e da Educação.

A norma é expressão de valores que vão se concretizando na dinâmica dos fatos histórico-sociais. O Direito é composto originalmente por esses três elementos relacionados dialeticamente: fato, valor e norma. Com isso, podemos afirmar que, essencialmente, o Direito tem por objetivo a tutela do que é relevante para a sociedade: valores, traduzidos em bens jurídicos, percebidos por meio das relações, e fatos nos quais envolvem-se os indivíduos, concretizados nas normas jurídicas.

A partir daí entendemos que não é possível conceber o Direito como mero instrumento abstrato a regular a vida individual das pessoas, mas sim fruto da relação social que elege, na forma dos dispositivos legais, o que deve ser virtude social e o que deve ser colocado na condição de ilícito. Importa, assim, determinar o significado do Direito à luz da experiência social e histórica do ser humano.

Já a Educação pode ser entendida como a formação humana mais geral em uma sociedade. Toda sociedade acaba por definir qual indivíduo é ideal para nela viver e agir e, dessa forma, os comportamentos são definidos socialmente. O conteúdo escolar de uma determinada sociedade passa, necessariamente, pelo conteúdo da sociedade como um todo. Cada conjunto de pessoas de uma mesma esfera, considerado em momento determinado de seu desenvolvimento, possui um sistema de educação que se impõe aos indivíduos de modo geralmente irresistível.

Resulta desses fatos que cada sociedade tem seu homem certo, ideal, tanto do ponto de vista intelectual, quanto do físico e moral; a sociedade, em seu conjunto, e cada meio social em particular, é que determinam este ideal a ser realizado. E não poderia existir sem que houvesse em seus membros certa homogeneidade: a educação perpetua e reforça essa 
homogeneidade fixando de antemão na mente dos indivíduos certas similitudes essenciais, reclamadas pela vida coletiva.

Constituir um ser social no seres humanos é o fim da educação, um sistema de ideias, sentimentos e hábitos que exprimem nas pessoas, no grupo ou grupos diferentes de que fazem parte; tais são as crenças religiosas, as crenças e práticas morais, as tradições nacionais ou profissionais, as opiniões coletivas de toda a espécie. Seu conjunto forma o ser social.

É a sociedade que lança o indivíduo fora de si mesmo, que o obriga a considerar outros interesses que não os próprios, que o ensina a dominar as paixões, os instintos, e dar-lhes lei, ensinando-os a subordinação dos fins individuais aos coletivos. Todo o sistema de representação que mantém no ser humano a ideia e o sentimento da lei, da disciplina interna ou externa, é instituído pela sociedade e a mesma constrói isto por meio daquilo que é chamado de Educação.

Mas, se por um lado a Educação é o que forma os indivíduos, propiciando que se internalizem os valores estabelecidos em determinada sociedade desde seus primeiros passos, e ao Direito, por outro lado, cabe regular as relações estabelecidas por esses indivíduos, de acordo com os mesmos valores, então podemos concluir que a educação compõe a base do cumprimento legal de uma sociedade. E, ainda, se o Direito é constituído de valores a serem cumpridos, e a Educação tem o papel de formar os seres humanos dentro desses valores, há uma relação mútua e socialmente fundamental entre o Direito e a Educação.

A Educação é um processo integral de formação, pois cada ser humano, ao nascer, precisa receber uma nova condição para poder existir socialmente. Essa existência social implica em atender as expectativas estabelecidas, e atendê-las passa pelo cumprimento das leis, pela internalização das regras vigentes, isto é, pela observância do Direito.

Portanto, há uma acentuada vinculação entre Educação, Direito e a ação formadora do ser humano, pois o Direito, que possui papel regulador e de formador de valores sociais, tem papel fundamental na Educação de um povo, assim a Educação possui papel essencial para o cumprimento do Direito.

A minoria dos indivíduos de uma sociedade possui domínio direto do Direito vigente, porém os valores fundamentais adotados pela sociedade, que depois são positivados na letra da lei, ou seja, os bens jurídicos relevantes, esses sim, são internalizados por todas as pessoas sob a égide de determinado Direito vigente; esse fato não se dá por um ensinamento direto da letra da lei, mas pelo processo educacional, pela ação formadora dos seres humanos.

Há que se observar outro aspecto importante dessa vinculação entre o Direito e a Educação: a confecção do Direito como um produto social. Os juristas, ao proporem para a sociedade determinadas normas que elaboram, não as fazem com isenção dos seus valores, valores que recebem de seu contexto social, por isso, tanto no cumprimento do Direito quanto na elaboração das normas vigentes, a educação está presente ao assegurar os valores sociais no processo de formação dos indivíduos, tanto em quem cumpre as normas, como também em quem, além de cumpri-las, as elabora. Conforme Hespanha (2005, p. 38):

Contudo, o direito em sociedade não consiste apenas em considerar o papel do direito no seio de processos sociais (como o da instauração da disciplina social), mas também em considerar que a própria produção do direito (dos valores jurídicos, dos textos jurídicos) é, ela mesma, um processo social. Ou seja, algo que não depende apenas da capacidade de cada jurista para pensar, imaginar e inventar, mas de um complexo que 
envolve, no limite, toda a sociedade, desde a organização da escola, aos sistemas de comunicação intelectual, à organização da justiça, a sensibilidade jurídica dominante e muito mais.

Com isso, podemos dizer que tanto o Direito quanto a Educação são instrumentos de um projeto de sociedade, projeto este desenvolvido e constituído historicamente por cada geração. Cada período possui suas condições objetivas e subjetivas, e os indivíduos existentes em determinado momento histórico reagem a essas condições dialogando com o percurso histórico das gerações passadas, elaborando, assim, coletivamente, valores que formam, ainda que intuitivamente, o projeto da sociedade de cada período.

Portanto, se consideramos que a Educação e o Direito fazem parte de um projeto geral, forjado por meio das condições históricas e culturais que compõem determinado período e povo, se faz necessário a análise de tais condições que compõe cada sociedade. Afirmamos ser o Direito e a Educação parte de um conjunto de elementos que constituem toda uma identidade social tanto dos indivíduos como coletiva, porém, assim como o Direito e a Educação são elementos que influenciam a sociedade e se impõe sobre ela, são, antes, uma criação resultante da mesma. Cada sociedade, a partir de seus recursos e a relação humana que se estabelece com eles e entre si, criam interpretações, elegem valores, acumulam, aplicam conhecimentos, isso é, constituem uma mentalidade, uma cultura que no seu desdobramento e exercício constante e cumulativo dão origem a estruturas complexas como o Direito e a Educação.

Antes, porém, de analisarmos mais a fundo como se constituiu tais elementos em Portugal do século XVI, que é nosso objetivo final, precisamos entender como eles, o Direito e a Educação, foram constituídos. Faremos isso pelo estudo da identidade portuguesa do século XVI e quais elementos compuseram a cultura e a mentalidade dessa sociedade, que depois, ou conjuntamente, resultarão na criação de sistemas educacionais e jurídicos.

\section{A MENTALIDADE PORTUGUESA DO SÉCULO XVI}

O estudo da mentalidade portuguesa se dará em três pontos fundamentais e indissociáveis: o regime político - a monarquia e especificamente a figura do rei e sua representação social -, o regime econômico, baseado na expansão marítimo-comercial, e uma análise da religiosidade católica e o papel da Igreja na formação daquela cultura.

A cultura geral da sociedade quinhentista é religiosa, pois a dinâmica social não apontava para um rompimento com a idéia de que ser súdito era praticamente sinônimo de ser cristão. Os portugueses se compreendiam tendo por base uma visão da realidade fundada sobre marcos teológicos cristãos, os quais foram sedimentados ao longo da Idade Média.

Os marcos justificavam "[...] a ordem social e o poder político, modelando o discurso, os valores, os comportamentos, os hábitos, a etiqueta, a visão de mundo, as relações interculturais, modelando cada gesto da vida social", e para além de possíveis interpretações práticas acerca do significado do religioso na vida dos homens, "tem-se que afirmar a mesma qualidade de origem: a realidade era compreendida religiosamente; os homens viviam no círculo de Deus, Deus participando da vida dos homens" (PAIVA, 2006, p. 114).

A cultura religiosa estava baseada na idéia de uma ordem universal, que dispunha as coisas de forma interligada, gerando a compreensão de uma finalidade última para existência de todas as coisas: 
O pensamento social e político medieval é dominado pela idéia da existência de uma ordem universal (cosmos), abrangendo os homens e as coisas, que orientava todas as criaturas para um objectivo último, que o pensamento cristão identificava com o próprio criador. Assim, tanto o mundo físico como o mundo humano não eram explicáveis sem a referência a esse fim que os transcendia, a esse "telos", a essa causa final (para utilizar uma impressiva formulação da filosofia aristotélica); o que os transformava apenas na face visível de uma realidade mais global, cujo (re)conhecimento era indispensável como fundamento de qualquer proposta política. (XAVIER; HESPANHA, 1993, p. 122).

A ordem universal é explicada por uma unidade que lhe dá vida e que dispõe as responsabilidades. A unidade supõe as partes integradas num todo e, ao mesmo tempo, explicitando suas atribuições específicas. Tal unidade é verificada pelo papel que tem o Rei no corpo social, pois ele é a cabeça, é quem dirige o corpo e lhe dá função e importância.

$\mathrm{Na}$ ótica medieval, que persiste na lógica político-religiosa da época colonial, havia a concepção de que o rei tinha dois corpos: um real e outro místico, um natural e outro político:

O Rei possui duas capacidades, pois possui dois corpos, sendo um deles um Corpo Natural, constituído de Membros naturais como qualquer outro Homem possui [...]; o outro é um Corpo Político, e seus respectivos Membros são seus Súditos, e ele e seus Súditos em conjunto compõem a Corporação, [...] e ele é incorporado com eles, e eles com ele, e ele é a Cabeça, e eles os Membros, e ele detém o Governo exclusivo deles. (KANTOROWICZ, 1998, p. 25).

A função de quem governa é preservar o que é governado:

A função da cabeça ("caput") não é, pois, a de destruir a autonomia de cada corpo social [...], mas a de, por um lado, representar externamente a unidade do corpo e, por outro, manter a harmonia entre todos os seus membros, atribuindo a cada um aquilo que lhe é próprio [...], garantindo a cada qual o seu estatuto ("foro", "direito", "privilégio"); numa palavra, realizando a justiça. (XAVIER \& HESPANHA, 1993, p. 123).

A condição do rei de ser "cabeça" é que viabilizava o seu comando sobre a ordem social, que possibilitava o exercício pleno de seu poder. É exatamente pela via políticoreligiosa que o rei se punha para a sociedade como a sua maior autoridade. A ideologia medieval religiosa de que o rei representava uma ordem divina sustentava a posição central da realeza, da Coroa, moldando a forma de suas relações com os súditos, os quais, por sua vez, deviam a ele, antes de tudo, subordinação. Subordinação representa a manutenção da ordem, pois é a ordenação em seus mais variados ramos; há ordem, há quem ordena e há quem exerça a sub-ordem, ou seja, esteja, ordenadamente, subordinado (PAIVA, 2008). É a lógica da monarquia.

A principal tarefa do rei era, portanto, dispensar a justiça. No entanto, a justiça não pode ser vista apenas por princípios abstratos, como que descolados da prática social, mas como aplicação dos direitos que consolidaram a estrutura social portuguesa.

A sociedade portuguesa, religiosa e monárquica, sofre uma mudança no período que vai do século XVI ao XVIII, mudança que, aos poucos, torna a sociedade menos 
clerical, menos dependente dos fundamentos teológicos. Esse processo, que é derivado ou acompanhado da emancipação do indivíduo que acontece com o final da era medieval, especialmente com a consolidação da razão mercantil, se reflete no Direito que acaba por tomar uma posição de destaque na prática social. A justiça vai tendo uma determinação precisa e objetiva na sociedade na qual está inserida.

Essa experiência (mercantil), porque teve efeito visivelmente favorável,
se estendeu, experiência que era, a todo o modo de ser da sociedade. O de
mais próprio ela tem é o voltar-se para o outro, interessadamente - a
razão desse voltar-se devendo também interessar ao outro. A mercadoria,
com efeito, mediatiza interesses. Assim, o mercantil qualifica a sociedade
moderna, moldando a ação humana nos seus mais diversos tipos. Agir
mercantilmente é tomar como modelo das relações sociais as relações
pautadas sobre compra e venda. Agir mercantilmente é estar em aberto
para, sempre no pressuposto de convencer o outro a comprar o que se lhe
passa, tocando-o pois em sua sensibilidade. A experiência mercantil deve
ter produzido uma euforia na sociedade, ninguém contrastando a
expansão do modelo para as demais esferas da vida social. Como
assinalei acima, este modelo desabrochou lenta e progressivamente
durante alguns séculos, se achando consolidado no século XVI. (PAIVA,
2006, p. 142, grifos no original).

É preciso ter em conta que a consolidação, no século XVI, de uma razão mercantil a guiar a vida dos homens na sociedade portuguesa significa uma importância maior do direito positivo, do direito civil, tornando-se cada vez mais independente da ciência teológica; mas não significa, por sua vez, que a sociedade deixou de lado uma cultura religiosa que a explicasse e a fundasse. $\mathrm{O}$ cristianismo continuou pautando a vida das pessoas e influenciando decisivamente a confecção das leis, e isso é um dado que não pode ser relegado.

Diante disso, ao percebermos o Direito como um produto social, ao estabelecermos um estudo sobre a realidade portuguesa no século XVI, partimos para o próximo passo: entender como se constitui o Direito português nesse período.

\section{O DIREITO PORTUGUÊS NO SÉCULO XVI}

As leis portuguesas até o século XIX eram consubstanciadas nas Ordenações Reais, que eram regulamentos que levavam o nome dos reis que as faziam elaborar ou compilar e que pretendiam dar conta de todos os aspectos legais da vida dos súditos. Os três principais conjuntos de leis portuguesas até o fim da monarquia foram: as Ordenações Afonsinas, as Ordenações Manuelinas e as Ordenações Filipinas.

As Ordenações Afonsinas foram criadas no reinado de D. Afonso V, que reinou em Portugal de 1438 a 1481. Elas são dividas em cinco livros que tratam desde a história da própria necessidade daquelas leis, passando pelos bens e privilégios da Igreja, pelos direitos régios e de sua cobrança, pela jurisdição dos donatários, pelas prerrogativas da nobreza e pela legislação especial para os judeus e mouros; o livro IV trata mais especificamente do chamado direito civil e o livro $\mathrm{V}$ diz respeito às questões penais.

As Ordenações Manuelinas, do rei D. Manuel I (1495 a 1521) foram publicadas pela primeira vez em 1514 e receberam uma versão definitiva em 1521, ano da morte do rei. A invenção da imprensa e a necessidade de correção e atualização das normas contidas nas Ordenações Afonsinas foram as justificativas para a elaboração das novas leis. A 
estrutura de cinco livros foi mantida, algumas leis foram suprimidas e/ou modificadas e um estilo mais conciso foi adotado.

As Ordenações Filipinas vieram à luz em 1603, durante o reinado de Felipe II (1598 a 1621). No período conhecido como União Ibérica, no qual Portugal foi submetido pela Espanha (1580 a 1640), foram concebidas as últimas leis que o reino lusitano teve até ver o fim na monarquia no século XIX. As novas Ordenações foram necessárias devido à atualização com o direito vigente, pois algumas normas já estavam em desuso e outras precisavam ser revistas. Felipe II, apesar de ser Espanhol, mostrando habilidade política, promulgou as novas leis dentro de um espírito tradicional respeitando as leis portuguesas, mantendo-se, inclusive, a mesma forma das Ordenações anteriores.

Definimos analisar as Ordenações Manuelinas, em seu livro V, por dois motivos: primeiro, por se tratar do ordenamento jurídico em voga quando o Brasil passou a ser organizado de forma politicamente centralizada em 1549 quando da vinda de um Governador-Geral; segundo, porque no livro V constam as leis penais, e ao elegê-lo como objeto de análise tivemos como parâmetro o fato de, ao longo da história, ser o direito penal o que tutela os bens jurídicos mais relevantes para a sociedade, aquilo que lhe é mais precioso e, em conseqüência, punido mais severamente.

Porém, antes de entrarmos na análise mais específica de como as características da sociedade portuguesa do século XVI estão presentes na letra da lei contida nas Ordenações Manuelinas, é necessário refletir acerca de como os valores sociais são traduzidos para a legislação, e para isso é fundamental entendermos o conceito de bem jurídico.

\section{OS BENS JURÍDICOS}

Toda sociedade, composta de seus indivíduos e todos os recursos que os cercam, possui bens, isso é, objetos, que são traduzidos objetiva ou subjetivamente na realidade, que possuem valor para os seres humanos. "A idéia de bem se relaciona com a utilidade, como condição para satisfazer uma necessidade do homem" (PRADO, 2007, p. 20). Com isso, ao analisar qualquer sociedade, poderíamos encontrar, relacionados com suas principais características e identidades, aquilo que lhe é mais precioso, isso é, seus bens fundamentais.

São esses bens fundamentais que vão dar origem ao bem jurídico que, segundo Welzel (1970, 378 p.), é um "[...] bem vital da comunidade ou do indivíduo, que por sua significação social é protegido juridicamente", isto é, bens jurídicos são bens sociais expressos na letra da lei por meio da tutela jurisdicional que condena e pune determinadas ações, e pela definição desses bens jurídicos podemos fazer uma leitura mais precisa das características e valores de determinada sociedade traduzidos na letra da lei.

Porém, o conceito acabado de bem jurídico, isto é, a tradução de valores sociais tutelados pela lei, de forma clara só se dá com o surgimento do Estado de Direito, com a instauração das Constituições que vão impor o Direito acima da soberania real. Portanto, ao falarmos de bem jurídico no Direito português do século XVI, não nos referimos a este conceito acabado, usado hoje para a análise do delito, mas de seu esboço, partindo do princípio de que todo o Direito tutelou questões importantes para a sociedade na qual foi vigente, e estas questões podem, sem dúvida, serem chamadas de bens, ainda que estejam, neste período, totalmente ligados a valores religiosos, e o delito ainda seja confundido, de certa forma, com pecado.

Isto posto, ao caracterizarmos a sociedade portuguesa do século XVI, percebemos alguns de seus valores fundamentais. Se as três marcas principais dessa sociedade são a religiosidade católica, o regime monárquico e a expansão marítima, é inevitável que se 
parta daí a análise dos principais valores sociais portugueses, vinculando, assim, esta análise à legislação penal vigente.

\section{ORDENAÇÕES MANUELINAS}

As Ordenações Manuelinas, em seu Livro V, iniciam-se condenando o crime de heresia. Tal delito, que consiste em qualquer divergência da doutrina religiosa cristã, obviamente emana da cultura religiosa, pois condena qualquer exercício de fé que destoe da crença dominante. Esse delito nos apresenta dado relevante quanto à organização do Estado Português, pois, para julgamento de crimes "espirituais" formava-se um tribunal clerical. Portanto a Igreja julgava, mas a execução das penas era tarefa do Estado. O crime de heresia, além de nos apresentar a marca cultural religiosa presente em Portugal no século XVI, nos apresenta uma marca histórica, pois é um pequeno retrato legal da Inquisição medieval. O condenado era muitas vezes responsabilizado por uma "crise da fé", pestes, terremotos, doenças e miséria social, sendo entregue às autoridades do Estado, para que fosse punido. As penas variavam desde confisco de bens e perda de liberdade, até a pena de morte, muitas vezes na fogueira, método que se tornou famoso, embora existissem outras formas de aplicar a pena.

Porém, neste ponto, podemos perceber que, apesar da Igreja estar presente no campo jurídico, coordenando o ato de julgar seus hereges, se afasta no processo de aplicação das penas. Isto demonstra, por um lado, a força institucional da Igreja Católica, que reserva para si o poder de apenas julgar, mas por outro lado, pode demonstrar um início distante de um processo de laicização do Estado, já que quanto a crimes de ordem espiritual há que se ter separação jurisdicional.

No entanto, independente de que forma as penas eram executadas, é relevante que o primeiro delito disposto na lei penal manuelina seja a heresia. Sem dúvida o bem tutelado por este título criminal é a religiosidade. Pois até mesmo o camponês mais simples, mais isolado da efervescência política portuguesa, poderia morrer sem nunca ouvir falar das terras de além mar, poderia não reconhecer o rosto de seu rei, mas os símbolos de sua religião, sem dúvida, lhe eram inconfundíveis.

Segundo Silva e Hespanha (1993, p. 19):

[...] os Portugueses não eram apenas isso; que eram também (e sobretudo) católicos, que eram (muito menos) europeus, que eram hispânicos; que eram, depois, minhotos ou beirões; vassalos do rei ou de um senhor; eclesiásticos, nobres ou plebeus; homens ou mulheres.

E não poderia ser diferente, porque os portugueses, antes de qualquer coisa, antes de se aventurarem pelos mares ou serem súditos de um rei, eram católicos, e a religiosidade configurava-se como sendo um ponto relevante da cultura portuguesa quinhentista, um dos bens mais precisosos dessa sociedade, tutelado rigidamente e, caso transgredido, duramente punido com morte cruel ou degredo.

O segundo delito que aqui trataremos é o crime de Lesa-Majestade. Este delito ao ser positivado nas Ordenações Manuelinas relaciona-se com o conceito de religiosidade, mas fundamentalmente nos remete a questão monárquica.

Se o primeiro delito, a heresia, é o crime contra a religião cristã, contra a Igreja, contra Deus propriamente, o crime de Lesa-Majestade é contra a Sua representação, isto é, o Rei e toda ordem estatal. Tal crime é considerado o pior de todos os crimes, e o criminoso comparado a alguém que carrega consigo a lepra, enfermidade incurável e degradante: 
Lesa-majestade quer dizer traição cometida contra a pessoa de Sua Sacra Majestade Imperial ou Seu Imperial Estado, que é tão grave e abominável crime, e que os antigos sábios tanto estranharam que o comparavam à lepra, porque, assim como esta enfermidade enche todo o corpo, sem nunca mais se poder curar, e impedir ainda aos descendentes de quem a tem e aos que com ele conversam, pelo que é apartado da comunicação da gente, assim o erro da traição condena o que a comete, e impede e infama os que de sua linha descendem, mesmo que não tenham culpa. (ORDENAÇÕES MANUELINAS, p. 15)

Há que se perguntar por que o crime de Lesa-Majestade se sobrepõe ao crime de heresia, já que os dois emanam fundamentalmente da religiosidade cristã. A questão perpassa pelo bem social em questão. No crime de heresia o bem violado pelo delito é a religiosidade em si, os símbolos religiosos, a Igreja. A violação desse bem apresenta menos risco para a ordem social, pois a Igreja, além de ser uma instituição forte, possuía sua representação diluída e ramificada por toda parte. Isso não significa que tal crime não era duramente punido. Porém, quanto ao crime de Lesa-Majestade ser o mais grave de todos, isso se dá por alguns fatores, por exemplo, pela questão da hereditariedade, pois o direito ao trono passava pela aliança de sangue. Portanto, a primeira conceituação do delito é a traição cometida contra a pessoa do rei, sua esposa e seus filhos legítimos. Isto se dá devido ao abalo no Estado que pode gerar o assassinato de um rei ou de seus descendentes. "[...] se alguém tratasse a morte de seu Imperador ou da Imperatriz Sua mulher, ou de algum de seus filhos ou filhas legítimos, ou a isso desse ajuda, conselho ou favor." (ORDENAÇÕES MANUELINAS, p. 16).

Não poderia haver substituições simples, porque a legitimação do rei passa pela aliança de sangue, símbolo de um Estado monárquico forte. Prova desta dificuldade fora a própria ascensão de D. Manuel I ao reino Português. D. João II morrera sem herdeiros, já que seu filho legítimo não viveu para substituí-lo e seu filho bastardo D. Jorge não conseguira legitimação do Papa para assumir o reino, e mesmo de ascendência feminina, D. Manuel fora a melhor saída na correlação das forças políticas existentes na época.

O rei era considerado uma figura única, que não poderia ser facilmente substituída e personificava o Estado e a religião. Portanto, a lesão à figura real fere o bem social e jurídico mais relevante no contexto português do século XVI. Porém, este delito não se restringe apenas a lesão ao rei ou a família real, mas a todo e qualquer símbolo ou organização real. $\mathrm{O}$ delito condena qualquer traição, incluindo em sua tutela até mesmo informações estatais. " [...] se alguém der conselhos ou informações aos inimigos do Imperador, por carta ou qualquer outro aviso, em Seu desserviço ou de seu Imperial Estado".(ORDENAÇÕES MANUELINAS, p. 16).

Isto se dá porque a primeira tarefa da legislação de um Estado é proteger a ordem que lhe promulga. Se a lei, em primeira instância, emana do Estado, este há que proteger fundamentalmente a si mesmo, pois o bem social e jurídico mais relevante de um Estado é sua própria legitimidade, sua própria ordem. Por isso, as penas imputadas ao ferimento de tal valor jurídico tão caro são as mais cruéis e alcançam inclusive as futuras gerações dos criminosos.

\footnotetext{
* Com relação as citações das Ordenações Manuelinas que, no original, encontram-se em português arcaico, optou-se aqui, por fazer atualização ortográfica, mas não gramatical, para o português moderno para facilitar a leitura corrente do texto.
} 
E em todos estes casos e cada um deles é propriamente cometido crime de lesa-majestade e havido por traidor o que os cometer. Sendo o cometedor convencido, por cada um deles será condenado que morra morte natural cruelmente, e todos os seus bens e títulos nobiliárquicos que tiver ao tempo da condenação serão confiscados para a Coroa do Império, posto que tenha filhos ou outros alguns descendentes ou ascendentes, havidos antes ou depois de ter cometido tais malefícios. (ORDENAÇÕES MANUELINAS, p. 17).

O terceiro ponto que revela a sociedade portuguesa do século XVI é o seu projeto econômico. A expansão marítima portuguesa está presente em praticamente todos os títulos do ordenamento manuelino. A lei revela aqui o seu comprometimento com um projeto de sociedade ao legislar colocando em grande parte dos delitos as penas de degredo, variando o tempo em que o delinqüente deveria permanecer nas terras de Além Mar.

Tais penas eram aplicadas preferencialmente a pessoas consideradas de alta classe. Em alguns crimes os nobres tinham substituídas as penas de açoites pelo degredo devido a sua privilegiada posição. Citamos como exemplo o crime previsto no Titulo X: trata de assassinato e porte de arma na corte; quanto ao porte de arma, vemos a diferença de tratamento jurídico entre os homens portugueses quinhentistas. $\mathrm{O}$ homem simples que "tirar sua arma" (usar a arma), mesmo sem ferir ninguém, deveria ser publicamente açoitado e ter sua mão decepada. Já o nobre será apenas degredado e, quanto mais grave o delito, maior o tempo do degredo.

E quanto aos que tiram arma na cidade ou vila, ou lugar, onde nós estivermos, ou a Casa de Suplicação sem nós, ou em seus arredores, e com ela ferir, ou ofender alguém fora de nosso paço e seu circuito, se for peão ou filho de peão, ou de mais baixa condição, e com ela não ferir, seja açoitado publicamente com baraço, e torne-se notório pela vila, ou lugar, onde isto acontecer (...) E se for cavalheiro, Vassalo, ou escudeiro, ou de outra semelhante qualidade, que não seja peão ou filho de peão (...) seja degredado por dois anos em Celta. (ORDENAÇÕES MANUELINAS, p. 44).

Este fato nos fornece dois dados. O primeiro, que os homens não eram iguais perante a lei, a hierarquia era clara e a sociedade organizava-se sem o compromisso liberal posterior da igualdade jurídica, e que tal situação era perfeitamente aceitável não se configurando um problema para aquela sociedade. O segundo, é que a desigualdade jurídica frente as penas de degredo especificamente nos fornece o dado de que tal feito representava o compromisso das leis com o projeto de colonização.

Nem todos os portugueses tinham o espírito de aventura daqueles que compunham a tripulação nas grandes navegações, porém, devido aos aventureiros e a vontade política real, as terras sob o domínio português só aumentavam, e por isso era preciso convencer ou forçar pessoas capazes de contribuir com o desenvolvimento das colônias a irem cumprir este papel.

Possivelmente, muitas ações positivas foram propostas para que houvesse voluntários a se aventurarem nas terras encontradas, mas as colonizações eram um projeto geral e compunha a base de sustentação de Portugal. E por isso, toda e qualquer face que compusesse essa sociedade estava comprometida com este projeto, principalmente as leis. 


\section{CONCLUINDO}

Assim, se conceituamos o Direito como a tutela de um conjunto de bens relevantes à uma sociedade, punindo condutas que os transgridam, então, afirmamos que o Direito penal português do século XVI, positivado nas Ordenações Manuelinas, não era diferente. A sociedade portuguesa possuía como bens sociais relevantes, oriundos de sua cultura construída historicamente, questões, já levantadas, como a religiosidade cristã, o regime monárquico e o projeto de expansão marítimo-comercial, e tais pontos são exacerbadamente encontrados na lei, tutelados pelo direito.

A cultura portuguesa, construída por muitos elementos subjetivos e objetivos no período quinhentista, teve no direito uma das principais estruturas que contribuíram para sua incorporação à identidade de cada indivíduo que compunha o reino. $\mathrm{O}$ direito, em primeiro plano, possui função de tutela, organização estatal, mas também pode, dialeticamente, exercer função pedagógica. $O$ direito não contribui apenas com a educação tutelando o que ela propõe ao indivíduo, como se fossem estruturas separadas, uma ensinando valores e a outra os fiscalizando e punindo quando transgredidos. Podemos citar, como função pedagógica do direito, os autos de fé liderados pela Inquisição, isto é, a punição pública de graves delitos para que todo o povo pudesse perceber o prejuízo que seria descumprir a lei. Como outro exemplo dessa ligação, a função jurisdicional da educação: a educação formal, sob a égide das escolas, possui hoje e possuía no século XVI, um sistema jurídico próprio, que favorecia aqueles que cumprissem as regras e punia aqueles que as descumprissem, fazendo com que indivíduos desde cedo vivessem a essência de uma ordem jurisdicional, sendo que muitos desses mesmos indivíduos mais tarde tornar-se-iam juristas ou legisladores, isto é, formados em um processo educacional.

Por isso, é preciso perceber o nexo, a ligação existente entre as várias estruturas de uma mesma cultura. Em primeiro plano, percebemos a relação de cooperação do direito e da educação, pois a educação ensina os seres humanos a conviver em sociedade, dominar suas paixões e perceber os limites de sua liberdade; já o direito garante que a ordem aconteça porque vigia, fiscaliza e pune caso a educação não se faça suficiente. Mas o fato é que ambos constituem-se sob os mesmos valores culturais. Mas não somente cada um desses elementos cumpre o seu papel em separado, havendo aí uma relação mais complexa, que nos mostra que o direito muitas vezes é educação, pois ensina e contribui com a internalização de valores e, vez por hora, a educação é direito, pois no processo educacional, primeiro ensina-se, porém, tutela-se e fiscaliza-se o que foi ensinado, e até mesmo pune-se ações que se contrapõe aos bens e valores ensinados.

\section{Referências}

HESPANHA, Antonio Manuel e SILVA, Ana Cristina Nogueira. A identidade portuguesa. IN: MATTOSO, José (dir). História de Portugal - no alvorecer da modernidade (14801620). Terceiro volume. Lisboa: Estampa, 1993.

HESPANHA, Antonio Manuel. A história do direito na história social. Lisboa: Livros Horizonte, 1982.

HESPANHA, Antonio Manuel. Cultura Jurídica Europeia. Síntese de um milénio.São Paulo: Brasileira, 2005.

KANTOROWICZ, Ernst H. (1957) Os dois corpos do rei: um estudo sobre teologia política medieval. São Paulo: Companhia das Letras, 1998 
ORDENAÇÕES MANUELINAS. Livro 5. Lisboa: Calouste Gulbenkian, 1984e.

PAIVA, José Maria de. Colonização e Catequese. São Paulo: Arké, 2006.

PRADO, Luiz Regis. Bem jurídico-penal e Constituição. São Paulo: Editora Revista dos Tribunais, 2007.

WELZEL, Hans. Derecho Penal Alemán. Tradução de Juan Bustos Ramírez e Sérgio Yánez Perez. 11 ed. Santiago: Ed. Jurídica de Chile, 1970.

XAVIER, Ângela Barreto \& HESPANHA, António Manuel. . A representação da sociedade e do poder. In: MATTOSO, José. História de Portugal. O Antigo Regime, 1620-1807. Lisboa: Estampa, 1993, t. IV, pp. 121-144.

Artigo recebido em: 15/05/2010

Aprovado em: 30/06/2010 